Crowley, N. (1955). J. gen. Microbiol. 13, 218-225

\title{
The Action of Streptococical Amylase in relation to the Synthesis of an Amylosaccharide by Amylolytic Strains of Streptococcus pyogenes
}

\author{
BY NUALA CROWLEY \\ Bacteriology Department, Royal Free Hospital School of Medicine, \\ at Royal Free Hospital, Gray's Inn Road, London, W.C. 1
}

SUMMARY: Streptococcal amylase behaves like $\alpha$-amylase, causing branch-chained substrates to lose viscosity with minimal release of reducing groups, and to become achromic with iodine. Reducing values equivalent to $50 \%$ of the theoretically obtainable maltose were reached after prolonged hydrolysis.

The enzyme was produced in high concentration by amylase-positive streptococci growing in simplified medium containing substrate. The same strains synthesized a starchy cell substance if grown in plasma-enriched medium containing either maltose or glycogen. When extracted by boiling with weak alkali the new product resembled amylose.

The resemblance of streptococcal amylase to $\alpha$-amylase was previously noted (Crowley, 1950, 1954). This paper describes a quantitative study of (1) a method of producing potent amylolytic cultures, (2) the amylase action, and (3) the production of a starchy cell substance by the same strains of group $\mathbf{A}$ streptococci.

\section{METHODS}

Strains. The strains of group A streptococci were SF130, type 1 and type 2/Opaque (both originally isolated by Dr F. Griffith), dried cultures of which were received from Dr Rebecca Lancefield. The strain T2/11020, type 2, had been dried in 1951 when freshly isolated, and was received from the Streptococcal Reference Laboratory.

Culture media. Infusion broth was made by the method of Todd \& Hewitt (1932). Peptone dialysate medium was prepared with Benger's peptone (Benger Laboratories Ltd., Holmes Chapel, Cheshire). A suspension of the peptone was dialysed against distilled water to obtain a solution containing c. $5 \%$ of the dialysable substances; to this were added $\mathrm{NaCl} 4.5 \mathrm{~g} . /$ l. and sodium $\beta$-glycerophosphate $6 \mathrm{~g}$./l. before sterilizing by filtration. Glutinous corn starch $4 \%, \mathrm{w} / \mathrm{v}$ (Amioca; Brown \& Polson Ltd, Wellington House, Strand, London, W.C. 2) was dissolved in $\mathbf{0 . 0 6 7} \mathrm{M}$-phosphate buffer, pH 7.6. This solution was autoclaved and added to the peptone dialysate in the proportion 1 vol. starch solution to $3 \mathrm{vol}$. peptone solution making a substrate concentration of $1 \%(\mathrm{v} / \mathrm{v})$ in the final medium

Measurement of amylase activity. (1) Viscosity reducing power was measured by a modification of the method of Christensen (1945), using Ostwald pipettes with a flow time for distilled water between 11 and 12.5 sec. at $26^{\circ}$. An enzyme sample $(0.5 \mathrm{ml}$.) was mixed with substrate $(4.5 \mathrm{ml}$.$) , and the flow time$ 
recorded at $2 \mathrm{~min}$. intervals. The substrate, either glutinous corn amylopectin $(1.5 \%, \mathrm{w} / \mathrm{v})$, or non-glutinous corn amylopectin $(4 \%, \mathrm{w} / \mathrm{v})$ was made up in 0.067 M-phosphate buffer and adjusted to an initial flow time of $65-75$ sec. at $26^{\circ}$. A fall of $1 \%$ in the viscosity (relative to water) of glutinous corn starch at $\mathrm{pH} 7 \cdot 0,26^{\circ}$, during $10 \mathrm{~min}$. was taken as equivalent to 1 unit of amylase. If $0.5 \mathrm{ml}$. of enzyme reduced the viscosity by $10 \%$ then $1 \mathrm{ml}$. of the sample contained 20 units.

(2) Saccharifying activity was measured by the method of Meyer, Fischer \& Bernfeld (1947) as modified by Noelting \& Bernfeld (1948). Colorimetric readings were made in a Unicam Spectrophotometer (SP 500) at $480 \mathrm{~m} \mu$. Purified corn amylopectin (intrinsic viscosity $1 \cdot 07$ ) was obtained from the Northern Regional Research Laboratory of the U.S. Department of Agriculture, Peoria, Illinois. Mussel glycogen was from a batch specially prepared by Light and Co. Ltd, Colnbrook, Bucks., England. Purified glutinous corn amylopectin was extracted from commercial Amioca.

$\mathrm{pH}$ values were measured by a direct recording $\mathrm{pH}$ meter (Electronic Instruments, Richmond, Surrey, England, Model 23). 5 l. or larger volumes of culture were continuously neutralized during incubation by an automatic $\mathrm{pH}$ controller made by Dr P. J. L. Sequeira, Pathology Department, Royal Free Hospital, which will be described elsewhere. The cultures were incubated in bottles, immersed to the neck in a temperature-controlled bath and were agitated continuously. Bacterial growth was measured turbidimetrically in the spectrophotometer at $650 \mathrm{~m} \mu$.

\section{RESULTS}

\section{The production of amylase in fluid medium}

Little or no amylase was found in $16 \mathrm{hr}$. Todd-Hewitt broth cultures of the strains T 1, T 2/opaque or T 2/11020. Enzyme was found after $24 \mathrm{hr}$., reached a maximum after 3 or 4 days at $37^{\circ}$ and usually decreased thereafter. The maximum amylase activity in the absence of substrate was usually less than three times that at $24 \mathrm{hr}$. Following the addition of a suitable substrate to the cultures a sharp rise occurred at any time during 7 days incubation at $37^{\circ}$. When the $\mathrm{pH}$ was kept at $7 \cdot 0$ for $6-8 \mathrm{hr}$. after adding substrate, the increase of enzyme was eight- to tenfold or more. During this period there was a threeto fivefold increase of bacterial growth. When the same strains were grown on starch agar and compared with replica cultures on other media, it was found that amylase was produced by certain colony variants (Crowley, 1954). It seemed probable that in selective cultures amylase-producing streptococci would outgrow the rest of the population. This hypothesis was tested by seeding heavy suspensions of streptococci from $24 \mathrm{hr}$. broth cultures into peptone water containing glutinous corn starch $(1 \%, \mathrm{w} / \mathrm{v})$, when good yields of amylase were obtained. The method was used to produce potent amylolytic cultures and cell-free filtrates which were relatively low in protein nitrogen. In subsequent experiments the medium was prepared with Benger's peptone, which contained dialysable substances supporting better growth than other culture media tested. 


\section{Growth and amylase production in simplified medium}

The following procedure was adopted. A dried culture was suspended in $2.5 \mathrm{ml}$. of broth and from this $1 \mathrm{ml}$. of growing culture was transferred to $10 \mathrm{ml}$. of broth which was incubated overnight at $37^{\circ}$. Serial subcultures $(10 \%$ inoculum) were made in $50 \mathrm{ml}$., $250 \mathrm{ml}$. and 1 l. of prewarmed broth at $2 \mathrm{hr}$. intervals, and finally into $5 \mathrm{l}$. which was incubated overnight at $37^{\circ}$. The streptococci were centrifuged down and the sediment was suspended in $110 \mathrm{ml}$. phosphate buffer. $100 \mathrm{ml}$. of the suspension was added to $300 \mathrm{ml}$. peptone

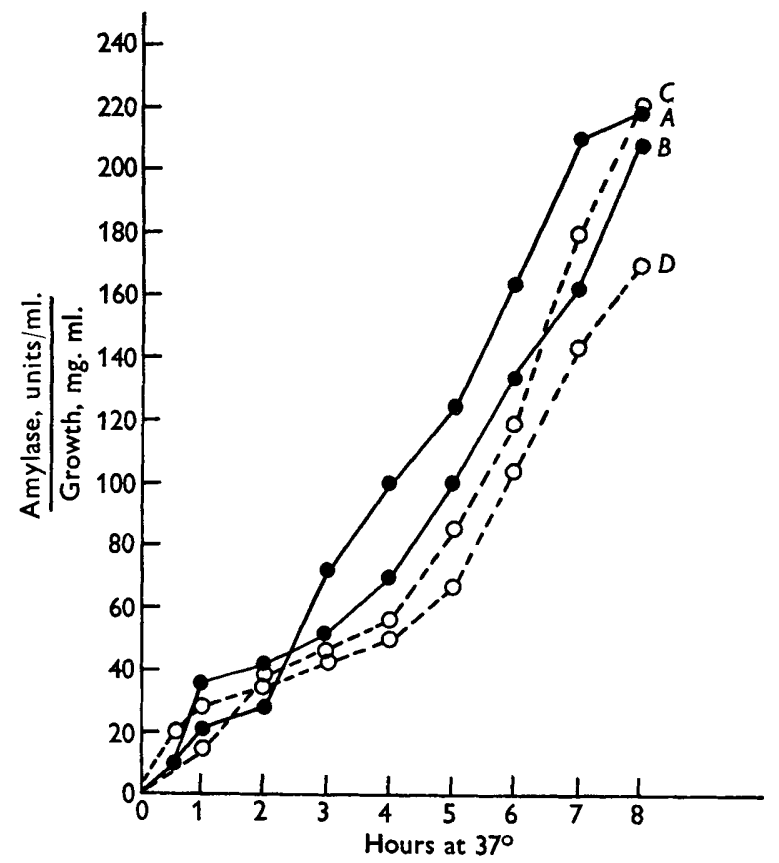

Fig. 1. The ratio of amylase to bacterial growth in the presence of starch substrate. type 1 cell suspensions. A, growth increase of $612 \cdot 3 \mathrm{mg} . / \mathrm{ml}$, ; and B, growth increase of $497.6 \mathrm{mg} . / \mathrm{ml}$. $\bigcirc----\bigcirc$, type 2 cell suspensions. C, growth increase of $637 \mathrm{mg} . / \mathrm{ml}$.; and $\mathrm{D}$, growth increase of $623.4 \mathrm{mg} \cdot / \mathrm{ml}$.

dialysate + starch substrate and incubated in a water bath at $37^{\circ}$ for $1.5 \mathrm{hr}$. The $400 \mathrm{ml}$. of culture was then added to $1 \cdot 61$. of fresh prewarmed medium and incubation continued for $6 \cdot 5 \mathrm{hr}$. The $\mathrm{pH}$ value was kept between $6 \cdot 8$ and $\mathbf{7 \cdot 4}$ by addition of $10 \% \mathrm{NaOH}$ solution. Culture samples $(25 \mathrm{ml}$.) were removed at hourly intervals, when bacterial growth was measured turbidimetrically and a cell-free filtrate was tested for amylase by the viscosimetric method. Four ml. supernatant were tested for presence of substrate by adding $1 \mathrm{ml}$. of iodine solution (iodine $5 \mathrm{~g}$., potassium iodide $10 \mathrm{~g}$., in $500 \mathrm{ml}$. of distilled water).

The ratio of amylase to bacterial growth during incubation of strains $\mathrm{T} 1$ and $\mathrm{T} 2$ /opaque is shown in Fig. 1. The cultures did not usually become 
completely achromic to iodine for $4 \cdot 5-5.5 \mathrm{hr}$. In the later experiments, the substrate was renewed after $4 \mathrm{hr}$. The bacterial cells were harvested in $110 \mathrm{ml}$. buffer, and $10 \mathrm{ml}$. of the suspension was compared with $10 \mathrm{ml}$. of the initial suspension. The remainder were frozen at $-10^{\circ}$ and used again. Dilutions of the initial suspension and final suspension were spread on blood agar and starch agar. From the final cultures, $95 \%$ or more of the colonies which grew on blood agar also grew on starch agar and were amylase-positive. For the strain $\mathbf{T} 1$ this was an increase of $25-35 \%$ in comparison with the initial culture, and for the strain $\mathrm{T} 2 /$ opaque, an increase of $5-15 \%$.

\section{Production of amylase by the selected population}

The thick suspensions of amylase-positive organisms described above yielded amylase in amount equal to or slightly above that of the primary culture when the cells were re-incubated for $\mathbf{5} \mathrm{hr}$. in fresh peptone + dialysate + substrate medium. When re-incubated a second time the yield was slightly decreased, but after a third re-incubation the yield was halved. It was evident that the amount of amylase obtainable was limited when the organisms were repeatedly subcultured in the simplified medium.

\section{The effect of cell-free filtrates on branched chain amylosaccharides}

Action on amylopectin. The viscosity reducing power and saccharifying activity of cell-free filtrates was measured using glutinous corn amylopectin and highly purified non-glutinous corn amylopectin as substrates.

Fig. 2 shows the fall in relative viscosity of glutinous and non-glutinous amylopectin in mixtures incubated at $26^{\circ}$, in which 1 vol. culture filtrate was incubated with 9 vol. substrate. The rate of attack on glutinous amylopectin was greater than on the non-glutinous, though the former was the more viscous substrate. At $37^{\circ}$ reduction in viscosity was too rapid to make useful measurements. Glutinous amylopectin showed increased turbidity during the initial stages of the reaction. This was followed by a progressive decrease of turbidity until the substrate became water-clear. The mixtures became achromic to iodine after the viscosity of the substrate was reduced by approximately $50 \%$.

Saccharifying activity. 1 vol. culture filtrate $+\mathbf{9}$ vol. substrate were incubated and samples removed at $10 \mathrm{~min}$. intervals during $1 \mathrm{hr}$. and thereafter at $2,4,8$ and $18 \mathrm{hr}$. Reducing values were expressed as percentages of the theoretically obtainable maltose, assuming that the maximum amount of maltose produced by $\alpha$-amylase from amylopectin was $80 \%$. Maltose production, initially small, showed a slow linear increase which continued after viscosity reduction had slowed down or ceased. Fig. 3 shows the ratio of maltose liberating activity to viscosity reducing activity when enzyme + substrate mixtures were incubated at $26^{\circ}$.

Action on glycogen. Glycogen (from mussels) when made up in $8 \%$ solution had only about one-third of the viscosity of $4 \%$ non-glutinous amylopectin. The action on glycogen was measured in terms of reducing power, dextrinizing 
power and decreased turbidity. At substrate concentrations of $4 \%$ or lower, reducing values were of the same order as those obtained with glutinous amylopectin. There was a transient increase of turbidity followed by progressive decrease. The preparation was stained reddish brown by iodine: the mixtures became achromic to iodine during the initial stage of increased turbidity.

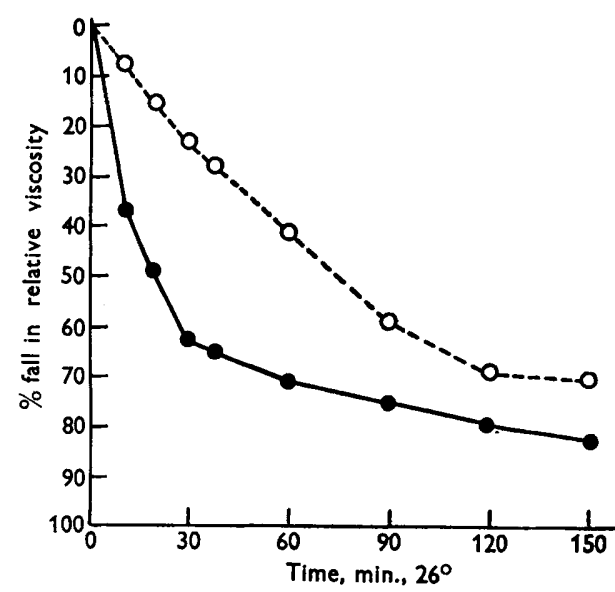

Fig. 2.

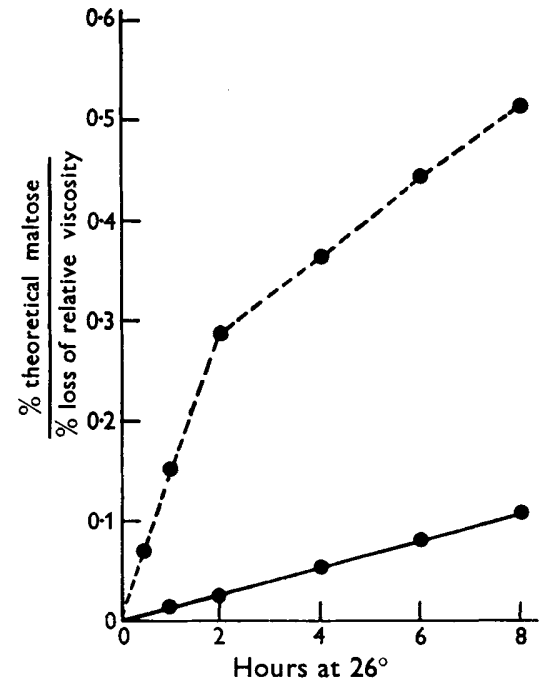

Fig. 3.

Fig. 2. The action of streptococcal amylase on amylopectin. - - , the substrate was glutinous corn starch $(2 \%, w / v)$ diluted in buffer to have an initial flow time of 70 sec. at $26^{\circ}$ at $\mathrm{pH} \% \cdot 0.0---0$, the substrate was purified corn amylopectin $(4 \%$, $\mathrm{w} / \mathrm{v}$ ) in buffer which had an initial flow time of 63 sec. at $26^{\circ}$ at $\mathrm{pH} \boldsymbol{\gamma} \cdot 0$. The ratio of enzyme (type 2 filtrate) to substrate was $1: 9$.

Fig. 3. The ratio of saccharifying activity to liquefying activity during hydrolysis of amylopectin by streptococcal amylase.

Ratio: $\frac{\text { percentage of theoretical maltose released }}{\text { percentage fall in viscosity relative to water }}$.

, with enzyme:substrate:: $1: 19$.

$0-----\bigcirc$, as above, with enzyme:substrate $:: 1: 1$.

The substrate was glutinous corn amylopectin with same type 2 filtrate as in Fig. 2.

Thus the amylase action on branched chain amylosaccharides was characterized by rapid decrease in viscosity, rapid dextrinization and minimal reducing values during the initial stages of the reaction. Reducing sugars increased steadily after the initial reaction had ceased. These properties are typical of $\alpha$-amylase, but the culture fitrates may have contained other enzymes, and two or more acting together may produce synergic or abnormal effects.

\section{The synthesis of a new amylosaccharide}

The amylase action which has been described appeared to be relevant to another finding, namely the production of a starch-like substance by the same strains growing in different cultural conditions. If heavy suspensions of 
amylolytic organisms were incubated in peptone dialysate medium containing $\mathbf{4} \%$ human plasma, and $\mathbf{0 . 4} \%$ of either glycogen or starch, little or no amylase was detected compared with the amount produced in the absence of plasma. Centrifuged sediments from $2 \mathrm{hr}$. culture samples were, however, stained pale blue by iodine solution, and later samples became dark blue or blue-black. This was due to a starch-like substance produced from maltose, in the absence of starch or glycogen, and the reaction did not therefore require an amylosaccharide as primer. Neither glucose-1-phosphate, glucose, cellobiose, melibiose, saccharose nor lactose was an alternative receptor for maltose.

Heavy suspensions of washed streptococci (strain T 2/11020) were incubated in a maltose-free medium, namely sodium $\beta$-glycerophosphate $(0 \cdot 6 \%, \mathrm{w} / \mathrm{v})$ glycogen $(0 \cdot 2 \%, \mathrm{v} / \mathrm{v})$ and human plasma $(8 \%, \mathrm{v} / \mathrm{v})$. After incubation for $30 \mathrm{~min}$. at $37^{\circ}$, blue-staining cocci were present in wet films treated with iodine. The starch-like substance was detectable macroscopically after $\mathbf{2 - 3} \mathrm{hr}$. incubation, the cultures staining with increasing intensity thereafter. Synthesis therefore took place in the presence either of maltose alone, or of glycogen alone with the help of something in human plasma. The cultures tended to become very acid during growth, and if the $\mathrm{pH}$ value was not continuously adjusted to about $7 \cdot 5$ the yield of starchy organisms was poor. The findings suggested that maltose, produced through the amylolytic breakdown of glycogen, was being used to build up a new amylosaccharide when cultural conditions were favourable for the synthesis.

\section{Extraction of the new amylosaccharide}

Heavy growth of starch-filled streptococci was obtained by growing the strain T 2/11020 in $5 \mathrm{l}$. or $8 \mathrm{l}$. cultures containing $\beta$-maltose, $10 \mathrm{~g}$./l. sodium $\beta$-glycerophosphate, $25 \mathrm{~g} . / \mathrm{l}$., Casamino acids, $10 \mathrm{~g} . / \mathrm{l}$. and human plasma, $10 \%, \mathrm{v} / \mathrm{v}$. The $\mathrm{pH}$ value was kept at 7.5 during incubation for $18 \mathrm{hr}$. More maltose (as $10 \%$ solution) was added after 5-6 hr. The streptococci were harvested and washed four times in phosphate buffer ( $\mathrm{pH} 8$ ). One vol. thick cell suspension in buffer was added to 3 vol. $0 \cdot 1 \mathrm{~N}-\mathrm{NaOH}$ held at $100^{\circ}$, at the rate of $50 \mathrm{drops} / \mathrm{min}$., and the mixture was mechanically stirred for $10 \mathrm{~min}$. after adding all the suspension, at a temperature just below boiling-point. After several hours at bench temperature the extract was centrifuged at

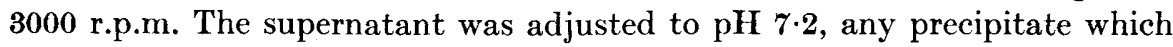

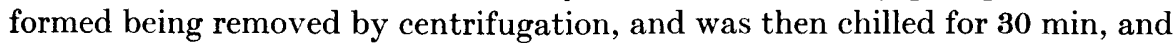
stirred into 4 vol. of cold ethanol. A heavy precipitate separated after standing overnight at $0^{\circ}$. This was washed in ethanol and acetone and dried in air, yielding a white powder which was stained blue by iodine. In addition to the iodine-staining material the crude substance contained peptides, protein and nucleic acid.

Properties of the starch-like substance. The powder was soluble in water at $\mathrm{pH} 8$, being more readily dissolved at $50^{\circ}$ or higher temperatures. The iodinestaining material did not diffuse through cellophane; it was precipitated by acetone, methanol, isopropanol, butanol, thymol and cyclohexanol thus 
resembling the amylose fraction of starch. The complex formed with iodine in neutral solution had a true blue tone; the colour either failed to develop, or faded rapidly, in weakly alkaline solution. Red tones appeared during hydrolysis in acid solution. Aqueous solutions contained occasional round or oval granules like starch granules. The alcoholic precipitates were crystalline, like the addition compounds formed by the amylose fraction of starch with alcohols.

After acid hydrolysis the crude dried substance which contained about $60 \%$ of organic material yielded reducing sugars including glucose. Samples of the amylosaccharide partially purified by precipitation with butanol contained another substance which had a maximum absorption at $260 \mathrm{~m} \mu$ and was probably nucleic acid. The properties of the amylosaccharide are being further studied.

\section{DISCUSSION}

By the degradation of branched chain amylosaccharides like glycogen, amylolytic strains of group A streptococci possess a mechanism for producing maltose which is not a normal constituent of animal tissues. In the presence of something provided by animal plasma, such strains could therefore utilize maltose obtained from glycogen to build up the new amylosaccharide. It has been shown that the synthesis begins within half an hour when amylolytic strains are placed in the appropriate environment. It is clearly possible that such strains may synthesize the starchy substance during passage in the host. Since amyloses readily form all kinds of addition compounds, the presence of the starch might alter the properties of streptococcal products which contribute to pathogenicity. This seems worth consideration with regard to the special types of inflammatory response associated with streptococcal infection in a minority of hosts.

Certain concomitant phenomena in amylolytic strains were previously noted (Crowley, 1954). Many strains freshly isolated from acute infections were untypable by $\mathbf{M}$ precipitin tests, and the serotypes most often associated with amylase production were antigenically exceptionally poor for preparation of type specific anti-M sera.

Part of this work was done at the Department of Microbiology, New York University College of Medicine, during the tenure of a William Marsden Travelling Professorship from the Royal Free Hospital Endowment Fund. I wish to thank Dr C. M. Macleod and Dr L. R. Christensen for their advice and help, and the Board of Governors of the Hospital who made the award. I also wish to thank Dr P. J. L. Sequeira and Dr I. Filshie, Pathology Department, Royal Free Hospital for many valuable suggestions.

\section{REFERENCES}

Christensen, L. R. (1945). Streptococcal fibrinolysis: a proteolytic reaction due to a serum enzyme activated by Streptococcal fibrinolysin. J. gen. Physiol. 28, 363.

Crowley, N. (1950). The degradation of starch by strains of group A streptococci having related antigens. J. gen. Microbiol. 4, 156. 
Crowley, N. (1954). On amylolytic strains of Streptococcus pyogenes. J. gen. Microbiol. 10, 411.

Meyer, K. M., Fischer, E. M. \& Bernfeld, P. (1947). Sur les enzymes amylolytiques. (1) L'isolément de l' $\alpha$-amylase du pancreas. Helv. chim. acta, 30, 64 .

Noelting, G. N. \& Bernfeld, P. (1948). Sur les enzymes amylolytiques. (3) La $\beta$-amylase: dosage d'activité et controle de l'absence d'- $\alpha$-amylase. Helv. chim. acta, 31, 286.

Tond, E. W. \& HewitT, L. (1932). A new culture medium for the production of antigenic haemolysin. J. Path. Bact. 95, 873.

(Received 14 December 1954) 